\title{
Surgical Treatment of Caudal Cranial Nerves Schwannomas: Literature Review and Analysis of Own Clinical Observations
}

\author{
Andrii Sirko ${ }^{1,2 *}$ and Rostislav Malyi ${ }^{2}$ \\ ${ }^{1}$ Departmentof Nervous Diseases and Neurosurgery, Dnipropetrovsk Medical Academy, Ukraine \\ ${ }^{2}$ State Establishment, Dnipropetrovsk Medical Academy, Ministry of Healthcare of Ukraine, Ukraine
}

*Corresponding author: Andriy Sirko, Dnipropetrovsk Medical Academy, the Ministry of Healthcare of Ukraine, Head of Cerebral Neurosurgery Department No.

2, Mechnikov Dnipropetrovsk Regional Clinical Hospital, Ukraine.

Received Date: April 23, 2019

Published Date: May 29, 2019

\section{Abstract}

Introduction: The group of non-vestibular schwannomas includes caudal cranial nerves schwannomas (CCNS). Tumors grow from one of the following cranial nerves: glossopharyngeal, vagus, and accessory nerves. Such tumors make up to $2.9-4.0 \%$ of all intracranial schwannomas.

Objective: Analysis of literature data and own clinical observations of CCNS, highlighting clinical features and surgical approaches in this type of neoplasms.

Material and methods: We have analyzed subject-related literature data in English. Three own clinical observations were analyzed. In all cases, 1.5 Tesla T1, T2, Flair, DWI, T1 IV-enhanced MRI and helical CT angiography were performed before the surgery. All patients underwent surgical treatment. Using a standard retrosigmoid approach, medullocerebellar cistern was opened and CSF was evacuated to relax the cerebellum. OPMI VARIO 700 microscope (Carl Zeiss, Oberkochen, Germany) Soring's ultrasonic tumor aspiration system was used for tumor removal. In a type D tumor patient, endoscopic assistance was used (Karl Storz endoscopy tower and 30-, 45-, and 70-degree endoscopes). Facial nerve function and caudal nerves function were neurophysiologically monitored using Nim Response 3.0 (Medtronic, Minneapolis, USA) at all surgery stages.

Results: In all cases, total resection of intracranial part of the tumor was performed. Bulbar disorders in two patients were temporary and only one patient had persistent bulbar disorders. Intraoperative neuromonitoring of facial nerve and caudal cranial nerves function is an important step in a surgery, which helps to reduce the risk of cranial nerves damage.

Keywords: Non-vestibular schwannomas; Caudal cranial nerves schwannomas; Surgical treatment; Intraoperative neuromonitoring

\section{Introduction}

Table 1: Typical radiological signs of caudal cranial nerves schwannomas.

\begin{tabular}{|c|c|c|c|}
\hline HCT & Bone window CT & MRI & Angiography \\
\hline & $\begin{array}{c}\text { Enlarged } \\
\text { Isodense } \\
\text { or weakly } \\
\text { hyperdense } \\
\text { even and well } \\
\text { identified bone } \\
\text { margins. No signs } \\
\text { of bone invasion. }\end{array}$ & $\begin{array}{c}\text { T1: hypo-/iso } \\
\text { intensive; } \\
\text { T2: hyper intensive; } \\
\text { T1, IV enhanced: } \\
\text { effectively } \\
\text { accumulates } \\
\text { contrast }\end{array}$ & $\begin{array}{c}\text { Weak or } \\
\text { moderate } \\
\text { vascularization }\end{array}$ \\
& & & \\
\hline
\end{tabular}

Caudal cranial nerves schwannomas (CCNS) include tumors growing from glossopharyngeal, vagus, and accessory nerves. Such tumors make up to $2.9-4.0 \%$ of all intracranial schwannomas. The ratio of caudal group schwannomas to vestibular schwannomas is $1 / 24$ [1-3]. According to research data, $90 \%$ of jugular foramen schwannomas originate from vagus and glossopharyngeal nerves [4]. Caudal cranial nerves schwannomas are slow-growing neoplasms with a non-infiltrative character of spreading. Exact determination of the nerve from which a tumor originates is a complex problem. Clinical picture depends on the nerve from which a tumor grows, its location, and size. First symptoms are headache (66\%), hearing loss (50\%), hoarseness (38\%), and dysphagia (38\%). Clinical picture in $81 \%$ of patients includes caudal group nerves dysfunction, $75 \%$ hearing loss, $44 \%$ cerebellar damage, 31\% lingual hemiatrophy, 25\% facial paresis, 13\% facial 
sensitivity disorder $[1,2,5,6]$. IV enhanced CT and MRI are the main diagnostic methods. Typical neuroimaging features of the CCNS are summarized in Table $1[3,7,8]$.
There are four types of tumors by nature of their spreading (Table 2):

Table 2: Jugular foramen tumors classification and appropriate surgical approaches.

\begin{tabular}{|c|c|c|}
\hline $\begin{array}{l}\text { Tumor Type According to the } \\
\text { Classification }\end{array}$ & Definition & Surgical Approach \\
\hline $\mathrm{A}$ & $\begin{array}{c}\text { Tumors with mainly intracranial component with } \\
\text { minimal jugular foramen invasion. }\end{array}$ & Retrosigmoid approach \\
\hline \multicolumn{3}{|c|}{ B } \\
\hline B1 & Tumors mainly located in jugular foramen & $\begin{array}{c}\text { Retrosygmoid infralabyrinthic (suprajugular) approach } \\
\text { with endoscopic assistance }\end{array}$ \\
\hline $\mathrm{B}_{2}$ & $\begin{array}{l}\text { Tumors mainly located in jugular foramen with more } \\
\text { expressed intracranial component }\end{array}$ & $\begin{array}{c}\text { Retrosygmoid infralabyrinthic (suprajugular) approach } \\
\text { with endoscopic assistance }\end{array}$ \\
\hline $\mathrm{B}_{3}$ & $\begin{array}{l}\text { Tumors mainly located in jugular foramen with more } \\
\text { expressed growth in infratemporal fossa }\end{array}$ & Transcervical approach with endoscopic assistance \\
\hline $\mathrm{C}$ & Tumors with extracranial growth & transcervical approach \\
\hline $\mathrm{D}$ & $\begin{array}{l}\text { Dumbbell tumors with extra- and intracranial } \\
\text { components. }\end{array}$ & $\begin{array}{l}\text { Combined retrosygmoid infralabyrinthic (suprajugular) } \\
\text { and transcervical approach with endoscopic assistance }\end{array}$ \\
\hline
\end{tabular}

Type A tumors have mainly intracranial component with minimal ugular foramen invasion.

Type B tumors are mainly located in the jugular foramen and have a smaller intracranial component

Type $\mathrm{C}$ tumors have extracranial growth

Type D is dumbbell tumors with extra and intracranial components [1] (Table 2).

CCNS treatment methods: case follow-up, surgical treatment, and radiation therapy. As such neoplasms are benign in most cases and do not show signs of infiltrative growth, total surgical resection is mainly preferred. According to the literature, the best result was obtained by total resection of small tumors that do not infiltrate adjacent nerves. In cases of large tumors that invade adjacent nerves, surgical dissection may cause neurological deficit (usually temporary). Choice of surgical approach depends on tumor type and prevalence $[2,9,10-13]$. Objectives of radiation therapy in the treatment of these tumors are to control tumor growth and avoid new neurological deficit both in primary radiation therapy and after subtotal tumor resection. The best results are obtained in small tumors [14-17]. Study objective: analysis of own clinical observations of CCNS, highlighting clinical features and surgical approaches in this type of neoplasms.

\section{Material and Methods}

Over the last 3 years (2016-2018 inclusive), 3 CCNS patients were treated at Neurosurgery Clinic of the Public Institution, Mechnikov Dnipropetrovsk Regional Clinical Hospital, Dnipro, Ukraine. They included two women and one man. Average age was $49.3 \pm 4.8$. Two tumors were located on the left, one on the right. All three patients complained of headache, dizziness, shaky walk, hearing loss (one patient had total hearing loss on the tumor side). Neurological status of all patients included intention tremor and past pointing at coordination tests, shaky posture during the
Romberg test. One patient had bulbar syndrome (nasal speech, difficult swallowing), horizontal and vertical nystagmus.

\section{Results}

\section{Neuroradiological features of tumors}

In all cases, 1.5 Tesla T1, T2, Flair, DWI, T1 IV-enhanced MRI and helical CT angiography were performed before the surgery to measure tumor vascularization and skull base bone destruction.

Patient 1: The tumor is located in the left cerebellopontine angle, $2 \mathrm{~mm}$ from the clivus, and spreads in caudal direction to the level of great occipital foramen. Mass is hypointense in T1 with no contrast enhancement and hyperintense in T2 (Figure 1). The fourth ventricle is partially squeezed and displaced to the right. IV enhanced brain MRI with intravenous shows $43 \times 50 \times 40 \mathrm{~mm}$ mass with uneven intensive contrast agent accumulation (Figure 2). CT angiography showed several necrosis foci within the mass, the mass causes an apparent compression of brainstem structures and is located near caudal nerve block (Figure 3). Right posteroinferior cerebellar artery is involved in arterial blood supply of the lesion. Venous outflow goes to lateral sinus and tentorial veins (Figure $1-3)$.

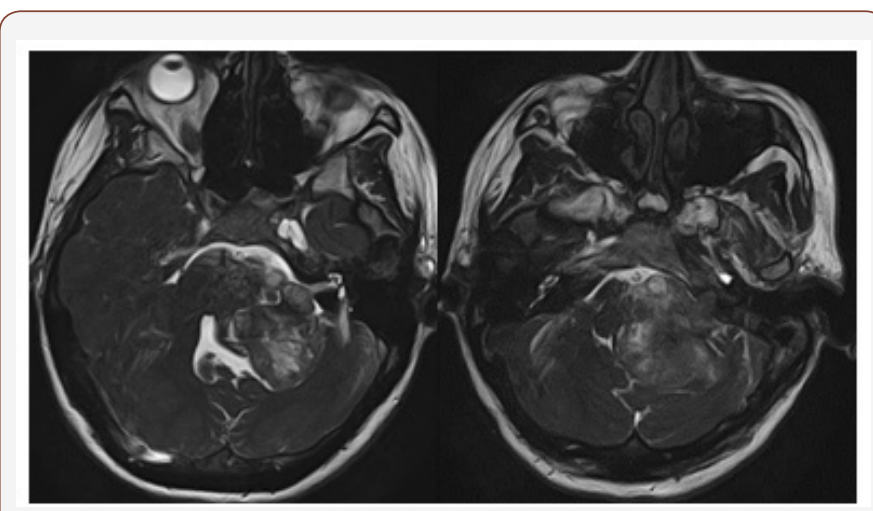

Figure 1: Preoperative MRI, T2-weighted image. 

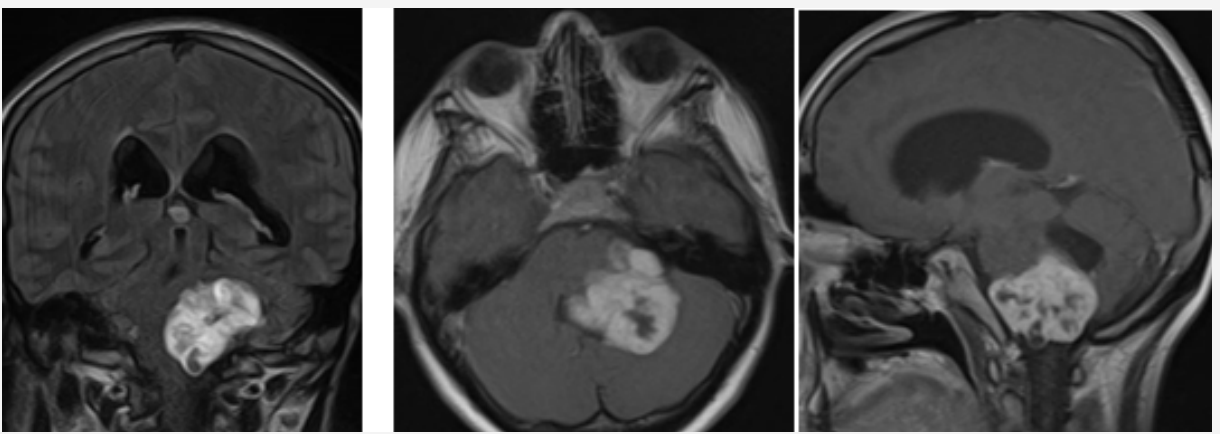

Figure 2: Preoperative MRI, T1+Gd.
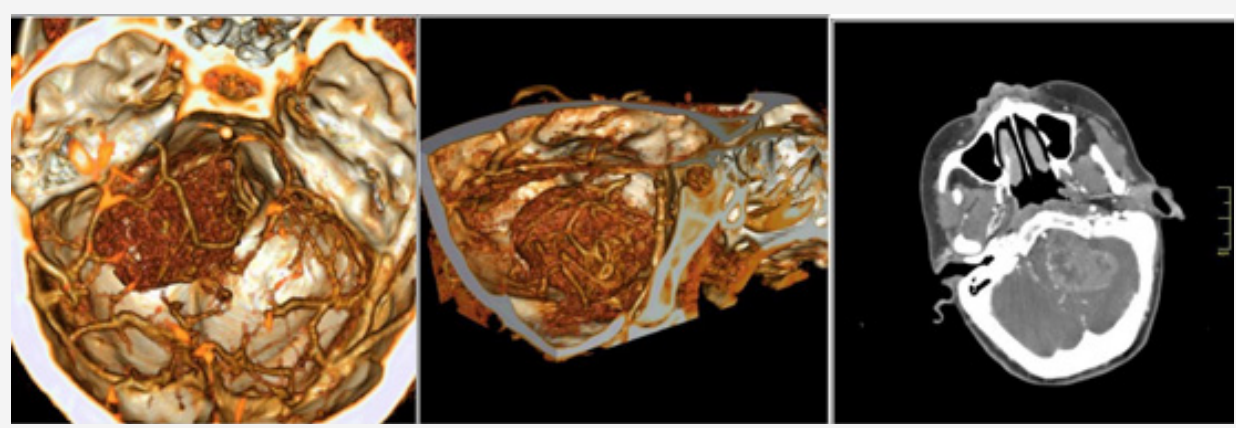

Figure 3: Preoperative CT-Ag.

Patient 2: The tumor spreads from the left jugular foramen to the left cerebellopontine angle and comes out extracranially under skull base through jugular foramen (Figure 4). IV enhanced brain MRI shows the neoplasm: axial size of intracranial tumor, $42 \times 27$ $\mathrm{mm}$. Sagittal size: intracranial part $30 \times 23 \mathrm{~mm}$, jugular foramen $17 \times 10 \mathrm{~mm}$, extracranial part $8.5 \times 6 \mathrm{~mm}$. The tumor intensively and homogeneously accumulates contrast agent (Figure 5). CT angiography shows destruction of jugular foramen and pyramid top. Arterial blood supply of the lesion involves branches of posteroinferior cerebellar artery and posterior cerebral artery. Venous outflow goes to lateral sinus from 2 sides. The fourth ventricle is partially squeezed and displaced to the right (Figure 4-6).

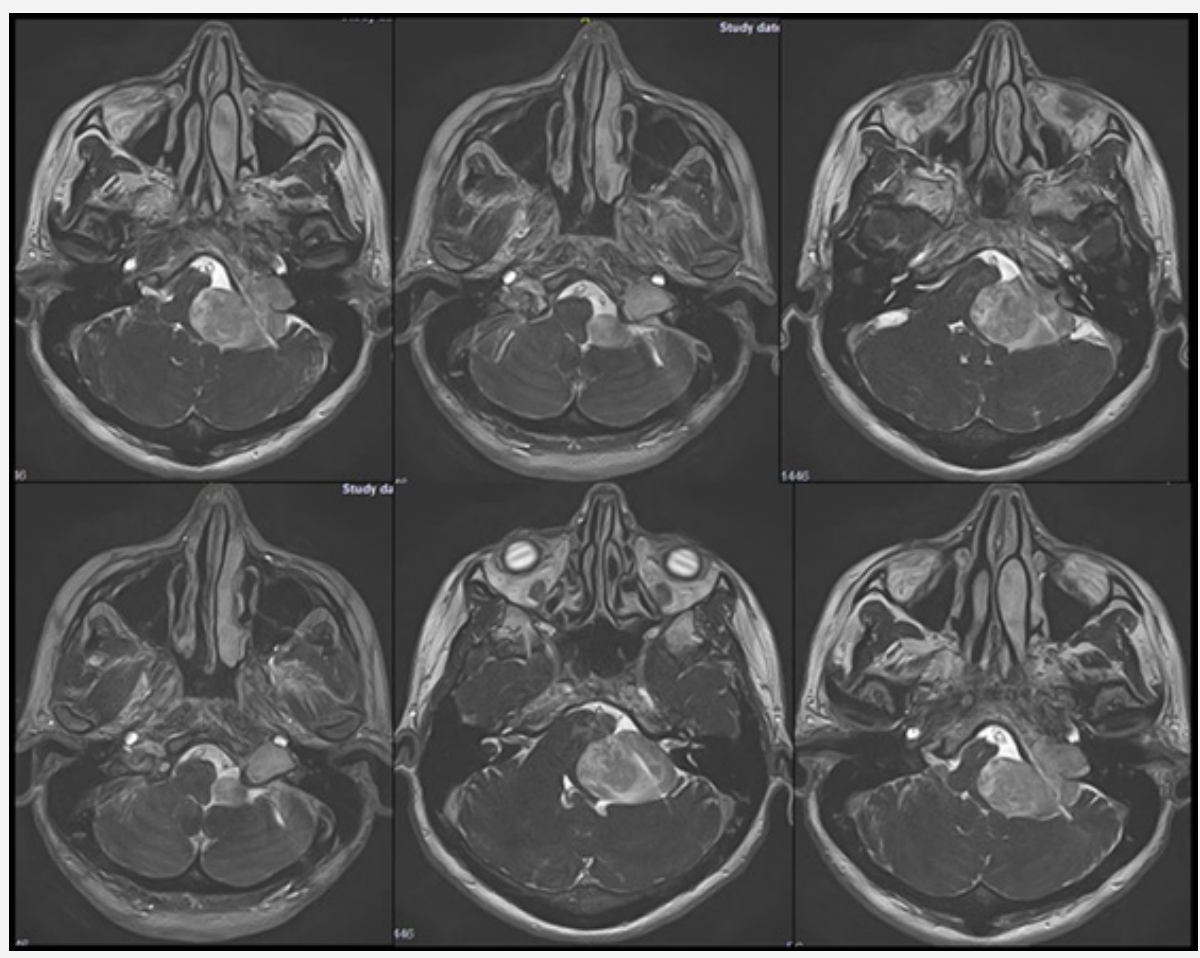

Figure 4: Preoperative MRI, T2-weighted image. 

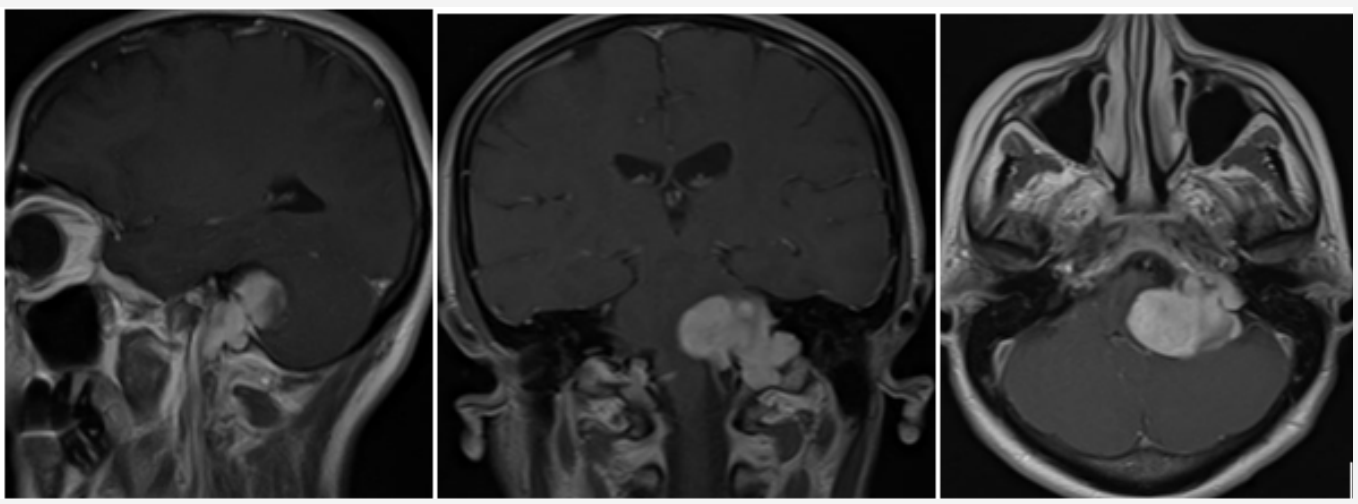

Figure 5: Preoperative MRI, T1+Gd. Sagittal, frontal, and axial plane.
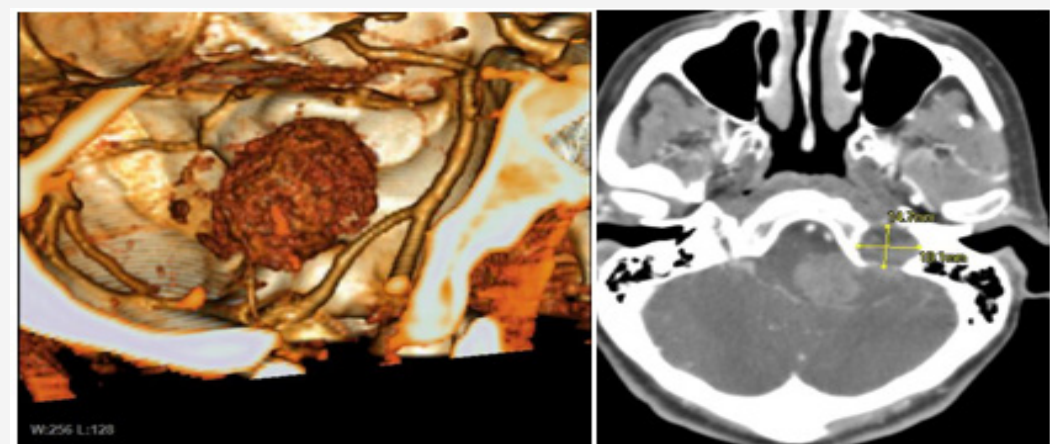

Figure 6: Preoperative CT-Ag. Destruction of left jugular foramen.

Patient 3: The tumor is located in the right cerebellopontine angle. IV enhanced MRI shows a cystic solid mass, $3.5 \mathrm{~cm}$ in diameter, which unevenly accumulates contrast agent. According to HCT angiography, branches of posteroinferior cerebellar artery
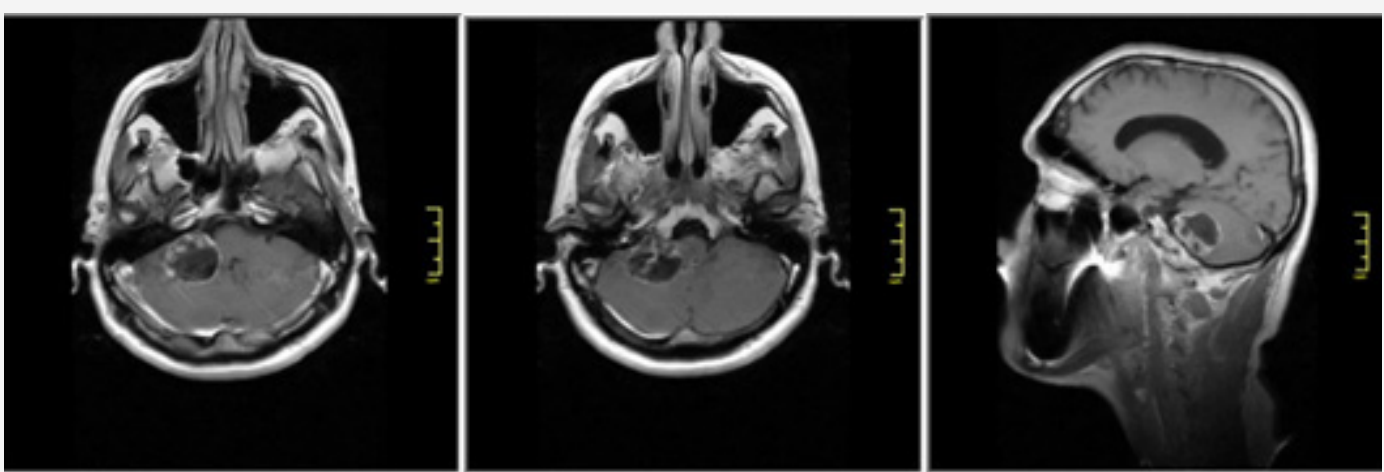

Figure 7: Preoperative CT-Ag. Destruction of left jugular foramen.

are involved in arterial blood supply of the lesion. Venous outflow goes to tentorial veins. The fourth ventricle is partially squeezed and displaced to the left (Figure 7 \& 8).

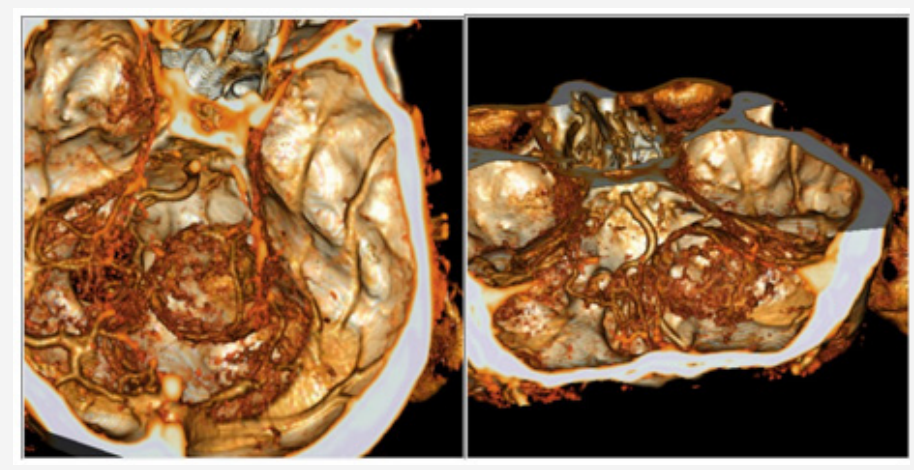

Figure 8: Preoperative CT-Ag. 
Given the data of radiological studies of neoplasms in patients 1 and 3, the patients were classified as type A; patient 2, type D. In all cases, tumors were supplied with blood from branches of posteroinferior cerebellar artery. In all cases, there was an apparent brainstem compression and fourth ventricle shift.

\section{Discussion}

\section{Treatment}

Surgical treatment was performed for all patients in lateral position with upper body raised by 45 degrees. Using a standard retrosigmoid approach, medullocerebellar cistern was opened and CSF was evacuated to relax the cerebellum. OPMI VARIO 700 microscope (Carl Zeiss, Oberkochen, Germany) Soring's ultrasonic tumor aspiration system were used for tumor removal. In a type D tumor patient, endoscopic assistance was used (Karl Storz endoscopy tower and 30-, 45-, and 70-degree endoscopes). Facial nerve function and caudal nerves function were neuro physiologically monitored using Nim Response 3.0 (Medtronic, Minneapolis, USA) at all surgery stages. In all cases, total resection of intracranial part of the tumor was performed. Periosteal graft on a pedicle and application of Tachokomb plates were used for dura mater closure. The bone was fixed with titanium miniplates and screws. Histological study in all three cases confirmed the presence of benign schwannoma (Grade I).

\section{Features of surgical technique in each particular case}

For patient 1, extended retrosigmoid approach was used. The incision was made in cervicooccipital area up to the level of spinous process of $\mathrm{C} 2$. In order to decompress posterior cranial fossa, a great occipital foramen and $\mathrm{C} 1$ arch were resected. Burr hole was made for left lateral ventricle posterior horn puncture. Ventricular puncture was performed. Distal end of ventricular catheter was lowered into spinal subdural space (Torkildsen drainage). Upper pole and upper lateral cerebellum were sparingly resected. Tumor process involved 7 and 8 cranial nerves, which were freely separated from the upper pole of the tumor. During the surgery, nerves 4, 5, 6, 7, 8 and the entire caudal group of cranial nerves were visualized and preserved. Jugular foramen was extended to $1.5 \mathrm{~cm}$. A followup confirmed completeness of tumor resection (Figure 9).

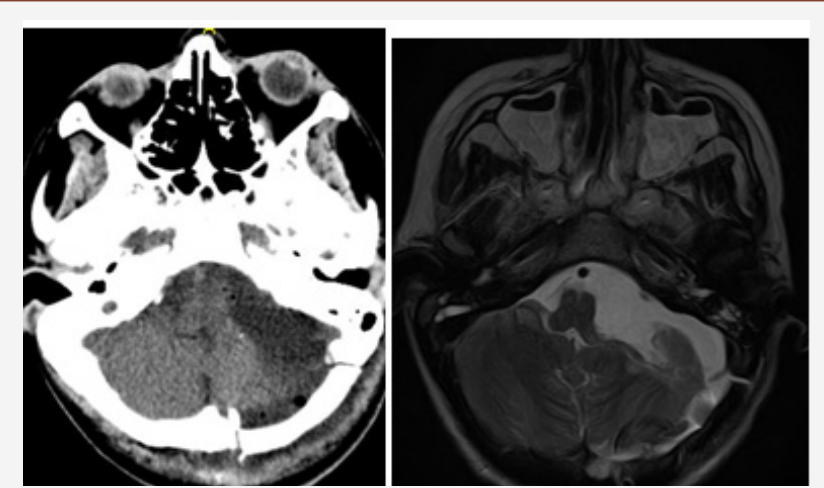

Figure 9: Postoperative follow-up. CT and T2-weighted MRI.

Patient 2 was treated with resection of intracranial part of the tumor. Upper pole and upper lateral cerebellum were sparingly resected. During the surgery, cranial nerves 5, 6 and 7 were verified and separated from the tumor sac. Facial nerve was located at upper pole of the tumor, it was well structured and slightly spread on the tumor. When caudal part of the tumor was removed, spontaneous electrical activity of the muscles innervated by cranial nerves IX and XI was reported. Caudal nerve group was spread and displaced in caudal direction. Jugular foramen was enlarged to $2 \mathrm{~cm}$. Initially, partial resection of intraforaminal part of the tumor accessible through retrosigmoid approach was performed. Remaining part of the tumor in jugular foramen was removed using endoscopic technique (Figure 10).

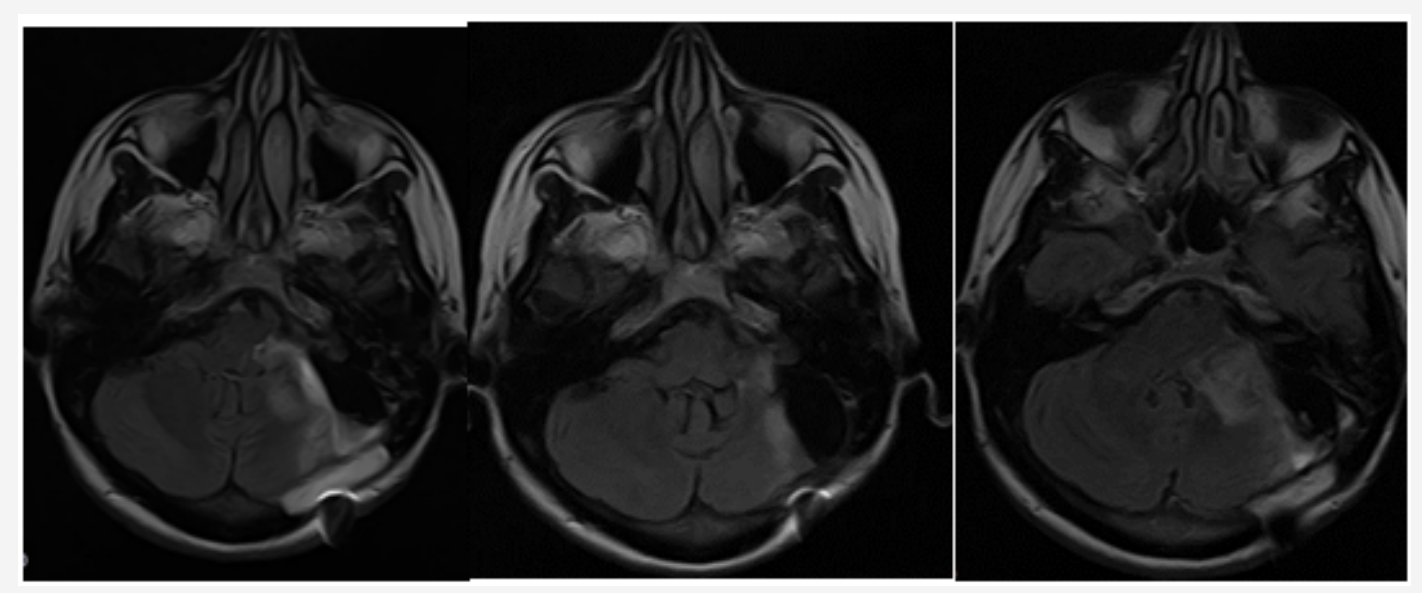

Figure 10: Postoperative follow-up MRI.

Patient 3: Upper pole and upper lateral cerebellum were sparingly resected. Facial nerve was located at upper pole of the tumor, it was well structured and slightly spread on the tumor. When caudal part of the tumor was removed, spontaneous electrical activity of the muscles innervated by cranial nerves IX was reported. Caudal nerve group was spread and displaced in caudal direction. Jugular foramen was enlarged to $2 \mathrm{~cm}$. Partial resection of intraforaminal part of the tumor accessible through retrosigmoid approach was performed (Figure 11). 

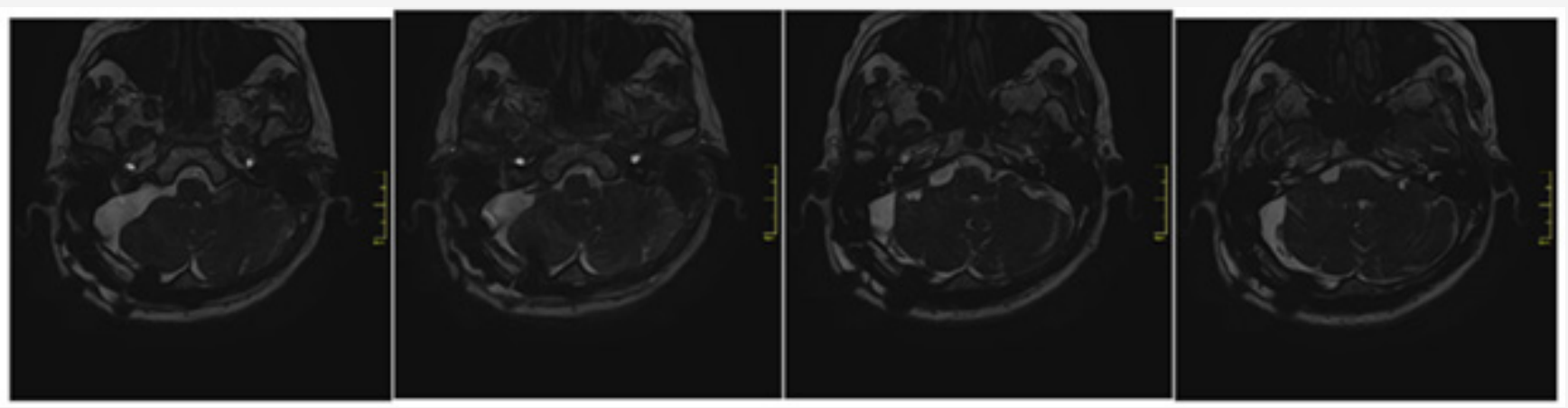

Figure 11: Postoperative MRI. T2-weighted image.

\section{Treatment outcomes}

All patients had headaches, coordination disorders, bulbar disorders (dysphagia, dysphonia), and hearing loss when discharged. Patients 1 and 2 had difficult postoperative period. Patient 1 underwent lower tracheostomy with further decannulation before discharge. No hydrocephalus was diagnosed. Patient 2 had postoperative occlusive hydrocephalus developed as a result of compression of the IV cerebral ventricle by postoperative edema. External drainage of lateral ventricle was performed to manage hydrocephalus, drainage was removed after 5 days. The patient was discharged with mild facial nerve paresis (House-Brackmann 2-3), the two other patients had no facial nerve paresis. Bulbar disorders in two patients were temporary and only one patient had persistent bulbar disorders. Patients are under follow-up monitoring. IV enhanced brain MRI is performed every 6 months.

\section{Conclusion}

Clinical picture of CCNS is quite often similar to that of vestibular schwannomas. A distinctive feature of caudal cranial nerves schwannomas is the presence of symptoms associated with damage of cranial nerves IX, X, XI. Neuroradiological study shows jugular foramen enlargement and destruction. Retrosygmoid approach is optimal for removal of type A, B1, B2 tumors and extracranial part of type D tumors. Given the location of caudal cranial nerves schwannomas, even if the integrity of surrounding tumor structures (cranial nerves, pons, medulla, arterial vessels, and venous sinuses) is preserved, postoperative period is associated with the risk of postoperative complications (occlusive hydrocephalus) and new neurological deficit. Neurological deficit severity is determined by tumor size and nature of its spreading. Intraoperative neuromonitoring of facial nerve and caudal cranial nerves function is an important step in a surgery, which helps to reduce the risk of cranial nerves damage. The use of angled endoscopes in assistant mode allows to resect a jugular foramen tumor. According to available reports, it is reasonable to use transcervical approaches to remove a extracranial part of the tumor.

\section{Acknowledgement}

The authors report no conflict of interest concerning the materials or methods used in this study or the findings specified in this paper.

\section{Conflict of Interest}

None.

\section{References}

1. Samii M, Babu RP, Tatagiba M, Sepehrnia A (1995) Surgical treatment of jugular foramen schwannomas. J Neurosurg 82(6): 924-932.

2. Nowak A, Dziedzic T, Czernicki T, Kunert P, Marchel A (2014) Surgical treatment of jugular foramen schwannomas. Neurol Neurochir Pol 48(3): 188-195

3. Zeng XJ, Li D, Hao SY, Wang L, Tang J, et al. (2016) Long-Term Functional and Recurrence Outcomes of Surgically Treated Jugular Foramen Schwannomas: A 20-Year Experience. World Neurosurgery 86: 134-146.

4. Song MH, Lee HY, Jeon JS, Lee JD, Lee HK, Lee WS (2008) Jugular foramen schwannoma: analysis on its origin and location. Otol Neurotol 29(3): 387-391.

5. Kankane VK, Warade AC, Misra BK (2019) Nonvestibular schwannoma tumors in the cerebellopontine angle: A single-surgeon experience. Asian J Neurosurg 14: 154-161.

6. Shibao S, Hayashi S, Yoshida K (2014) Dumbbell-Shaped Abducens Schwannoma: Case Report. Neurologia Medico-Chirurgica 54(4): 331336.

7. Eldevik OP, Gabrielsen TO, Jacobsen EA (2000) Imaging fi ndings in schwannomas of the jugular foramen. AJNR Am J Neuroradiol 21(6): 1139-1144.

8. Komune N, Matsushima K, Matsushima T, Komune S, Rhoton AL (2015) Surgical approaches to jugular foramen schwannomas: An anatomic study. Head \& Neck 38(S1): E1041-E1053.

9. Samii M, Alimohamadi M, Gerganov V (2015) Surgical treatment of jugular foramen schwannoma: surgical treatment based on a new classification. Neurosurgery 77(3): 424-432.

10. Ryu SM, Lee JI, Park K, Choi JW, Kong DS, et al. (2017) Optimal treatment of jugular foramen schwannomas: long-term outcome of a multidisciplinary approach for a series of 29 cases in a single institute. Acta Neurochirurgica 159(8): 1517-1527.

11. Kankane VK, Warade AC, Misra BK (2019) Nonvestibular schwannoma tumors in the cerebellopontine angle: A single-surgeon experience. Asian J Neurosurg 14: 154-161.

12. Jean WC, Felbaum DR (2016) Evolution of the Intracranial Approaches to Jugular Foramen Tumors: A Surgeon's Personal Perspective Through Three Illustrative Cases. Cureus 8(3): e530.

13. Matsushima K, Kohno M, Nakajima N, Izawa H, Ichimasu N, et al. (2019) Retrosigmoid intradural suprajugular approach to jugular foramen tumors with intraforaminal extension: surgical series of 19 cases. World Neurosurgery.

14. Park ES, Lee EJ, Park JB, Cho YH, Hong SH, etal. (2016) A Single-Institution Retrospective Study of Jugular Foramen Schwannoma Management: Radical Resection Versus Subtotal Intracranial Resection Through a 
Retrosigmoid Suboccipital Approach Followed by Radiosurgery. World Neurosurgery 88: 552-562.

15. Hasegawa T, Kato T, Kida Y, Sasaki A, Iwai Y, et al. (2016) Gamma knife surgery for patients with jugular foramen schwannomas: a multiinstitutional retrospective study in Japan. J Neurosurg 125(4): 822-831.
16. Liscak R, Urgosik D, Chytka T, Simonova G, Novotny J, et al. (2014) Leksell Gamma Knife radiosurgery of the jugulotympanic glomus tumor: longterm results. J Neurosurg 121: 198-202.

17. Langlois AM, Iorio Morin C, Masson-Côté L, Mathieu D (2018) Gamma Knife Stereotactic Radiosurgery for Nonvestibular Cranial Nerve Schwannomas. World Neurosurgery 110: e1031-e1039. 